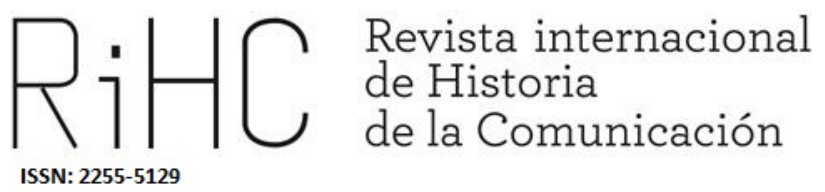

\title{
PROMOCIÓN Y REALIDAD EN CIFRAS DE UNA REVISTA CULTURAL DURANTE EL TARDOFRANQUISMO, LA ESTAFETA LITERARIA
}

Promotion and real figures of a cultural magazine during the last years of the Francoist Regime, La Estafeta Literaria

DOI: http://dx.doi.org/10.12795/RiHC.2019.i12.18

Recibido: $19 / 04 / 2019$

Aceptado: 18/05/2019

Publicado: $15 / 06 / 2019$

Ana Isabel Ballesteros Dorado

Universidad CEU-San Pablo, Madrid, España

ballesteros@ceu.com

ORCID (i) 0000-0001-8244-5326 
Resumen: Este artículo tiene por objetivo presentar ciertos documentos, inéditos hasta hoy, que permiten entender la evolución, entre 1971 y 1975, de una revista cultural española financiada por el régimen franquista, La Estafeta Literaria. Estos documentos resultan útiles en tanto ejemplos de cómo se realizaban las subvenciones estatales a los medios vinculados con el régimen durante los últimos años del franquismo, qué tipo de informes referentes a su evolución y beneficios económicos se solicitaban y qué medidas se adoptaban para garantizar el cumplimiento de sus objetivos. Los datos aportados en este artículo concuerdan con las conclusiones alcanzadas en otras investigaciones relativas a la prensa de este periodo. Sin embargo, frente a lo ocurrido con otras publicaciones financiadas por el Estado, logró perdurar durante la época de la Transición y solo acabaría después de la llegada al poder del Partido Socialista.

Palabras clave: La Estafeta Literaria, Revistas franquistas, Revista cultural, Historia del periodismo, Revistas españolas

Abstract: In this paper, the purpose is to introduce certain documents, unpublished until today, that make possible to understand the evolution, between 1971 and 1975, of a magazine financed by the Francoist regime, La Estafeta Literaria. These documents are useful as an example of how state subsidies were made to that press linked to the Francoist regime during its late years, what kind of reports about its evolution and economic returns were requested and what arrangements were adopted to ensure that it fulfilled its targets. The data shown in this article accord in a consistent manner with the conclusions reached in other investigations related to the press of this period. However, unlike what happened with other journals financed by the State, it managed to survive during the Democratic Transition and only ended after the Socialist Party entered the government.

Keywords: La Estafeta Literaria, Francoist Magazines, Cultural Magazine, Journalism History, Spanish Magazines

\section{Introducción y metodología}

El objetivo principal de este artículo consiste en exponer cómo se desarrolló durante los últimos ministerios del régimen franquista una revista cultural financiada por el Estado, La Estafeta Literaria (a partir de aquí, LEL). Así mismo, pretende confrontarse la evolución vivida por esta revista con las bases que, según opinión común de los historiadores, regían la política cultural del tardofranquismo y las disposiciones en materia periodística durante los primeros años setenta.

Se tiene el propósito de aportar una información que adquirirá mayor trascendencia conforme vayan desvelándose datos referentes a otras revistas culturales de la misma índole que los recopilados respecto a $L E L$, pues entonces cabrá establecer las oportunas comparaciones y lograr unas conclusiones de mayor calado. 
Con todo, se entiende que las conclusiones obtenidas por lo que respecta a esta publicación, sumadas a las que en un futuro puedan recogerse a partir del estudio de otras, sirvan para ofrecer una imagen veraz y más completa de lo ocurrido en este ámbito de la vida cultural durante los últimos años del franquismo.

El objeto principal del presente artículo puede cumplirse gracias al descubrimiento de una serie de documentos inéditos hasta hoy, conservados en el Archivo General de la Administración de Alcalá de Henares (a partir de aquí, AGA), referentes la revista $L E L$. Las cajas halladas en este archivo, con las signaturas 73/480, 73/481 y 73/482, se componen de fichas técnicas, presupuestos económicos, partidas de gastos e ingresos, así como de informes sobre el pasado de la revista y las previsiones de crecimiento y difusión de esta.

Los datos seleccionados para su examen pertenecen a la quinta etapa de $L E L$, en concreto a los años 1971-1975, tiempo durante el cual se modificaron muchos de sus elementos para adaptarse al panorama periodístico español del momento y procurar mayor expansión, en consonancia con las sugerencias de un informe fechado en mayo de 1970 (AGA 54, 73/482), descrito anteriormente en algunos aspectos generales (Ballesteros, 2018), aunque sin terminar de aclararlos todos, ni de dar razón de ellos ni de sus consecuencias.

El resto de los trabajos relacionados con esta publicación se habían centrado en la participación en ella de determinados colaboradores, como Francisco Umbral (Garbisu, 2014), Juan Emilio Aragonés, Luis Molero Manglano o Julio Manegat (Ballesteros, 2017a, 2017b, 2017c); en el contenido de ciertas secciones, como la de teatros de su primera etapa (Nieto, 2010) o las dedicadas a las cuestiones lingüísticas (Fernández Martínez, 2010, 2012a, 2012b); las noticias sobre el mundo editorial (González Ariza, 2010), o el espacio asignado al examen de las obras de determinados autores (Ballesteros, 2002, 2004; Garbisu, 2004, 2010).

Hasta hoy, solo uno de estos trabajos (Ballesteros, 2018) proporcionaba datos fehacientes relativos a las cantidades exactas recibidas en $L E L$ por parte del Estado hasta 1971, a la situación económica en que se encontraba esta revista en 1969 y a las nuevas disposiciones adoptadas tras elevarse el mencionado informe al Consejo de Ministros en 1970. Hasta tal año 2018, solo se contaba con unos pocos párrafos descriptivos en torno a la parte material de la revista, secciones y cambios de formato a lo largo de sus distintas etapas, escritos por Garbisu e Iglesias siguiendo exclusivamente del examen de sus páginas (véase, 2004: 11-18).

El presente artículo, por su parte, se asienta sobre el anterior de 2018, continúa la línea trazada respondiendo a los interrogantes marcados en sus conclusiones, y explana algunos documentos insertos en él a la luz de la situación política y de nuevos datos y documentos no recogidos en el anterior artículo sobre los años siguientes de $L E L$, años 
en que se llevaron a cabo diversas modificaciones y cupo observar las consecuencias en el desenvolvimiento de las ventas.

La presentación de los documentos seleccionados para el presente trabajo se plegará al método propio de la historiografía, consistente en ofrecer las pertinentes explicaciones de los datos para su oportuna comprensión, en el contexto de las circunstancias económicas y políticas de la España del momento en que tales documentos se redactaron y a consecuencia de los cuales se redactaron; y teniendo en cuenta, por supuesto, las peculiaridades de la publicación a la que tales datos se refieren, y sus diferencias frente a otras publicaciones coetáneas.

LEL, en su primera etapa (1944-1946), había dependido de la Delegación Nacional de Prensa, cuyo responsable, Juan Aparicio, la había fundado. Al renacer en 1956 LEL, creado ya el Ministerio de Información y Turismo, quedó vinculada a los suborganismos de este, es decir, a la Dirección General de Información, a la Dirección General de Difusión Cultural y, ya en los años sesenta y primeros setenta, a la Dirección General de Cultura Popular y Espectáculos. El Ateneo se encargaba administrativamente de ella hasta el 1 de marzo de 1964, en que Editora Nacional lo sustituyó en este cometido.

En el periodo objeto de este artículo, Ramón Solís Llorente percibía del Estado veintitrés mil trescientas pesetas brutas por dirigir LEL. El subdirector, Juan Emilio Aragonés, ganaba diecinueve mil ochocientas pesetas brutas mensuales $\mathrm{y}$, aunque redactaba también la sección de crítica teatral, no consta ninguna cuota añadida por este particular, ni ningún ingreso extra en calidad de colaborador. Eladio Cabañero, redactor jefe, tenía asignado el mismo sueldo que el subdirector, mientras que Manuel Ríos Ruiz por sus tareas de secretario de la Redacción recibía quince mil pesetas brutas. En calidad de redactor y encargado de la sección bibliográfica, figuraba en la mancheta Antonio Iglesias Laguna hasta el 15 de junio de 1972, en que le sustituyó Leopoldo Azancot, quien cobraría mensualmente la cantidad de ocho mil setecientas cincuenta pesetas brutas (AGA 73/481).

Como revista financiada por el Estado, LEL estaba supeditada a los movimientos gubernamentales, a las simpatías e intereses de quienes ocupaban los cargos en las instancias superiores, y no cabe deslindar su evolución de los objetivos ministeriales. Circunstancia sobradamente conocida, pero esencial para entender los motivos de las modificaciones experimentadas por la revista en estos años y los porqués de los documentos que van a presentarse, lo supone la tensión vivida entre los distintos grupos de poder dentro del Gobierno en la segunda mitad de los años sesenta y en los primeros setenta: de ahí que se sucedieran cuatro ministros de Información y Turismo durante el periodo que abarca este artículo, a saber, Alfredo Sánchez Bella entre el 29 de octubre

\footnotetext{
${ }^{1}$ Para entender el sentido de estas cifras, deben compararse con el salario mínimo interprofesional, establecido en tres mil seiscientas pesetas por el Decreto 720/1970, de 21 de marzo.
} 
de 1969 y el 11 de junio de 1973, Fernando de Liñán y Zofio hasta el 3 de enero de 1974, Pío Cabanillas hasta el 28 de octubre del mismo año, y León Herrera Esteban, hasta pocas semanas después de morir Francisco Franco. La orientación y las circunstancias de los gabinetes se reflejaron de una u otra forma en la trayectoria de $L E L$.

\section{Estancamiento y promoción de $L E L$}

\subsection{Situación de LEL al llegar Sánchez Bella al Ministerio y primeras disposiciones respecto a ella en 1970}

Las disensiones entre los grupos del Gobierno con diferente orientación ideológica habían conducido a varias situaciones de tensión en los años sesenta, entre las que destacó el caso Matesa, usado como arma arrojadiza contra el sector de los llamados "tecnócratas" (Álvarez Puga, 1974; Navarro, 1978). El asunto acabó con la destitución de once ministros en octubre de 1969, entre ellos el de Información y Turismo Fraga Iribarne -relacionado con el sector de los falangistas-, y con nuevos nombramientos gracias a los que, paradójicamente, pareció reforzarse el poder de los "tecnócratas". Alfredo Sánchez Bella, juzgado cercano a estos últimos, sustituyó a Fraga, y la aplicación de sus criterios, presumiblemente, deberían haber influido en las medidas adoptadas por lo que respecta a LEL: según diversos especialistas, el periodo de su ministerio se caracterizó por una vuelta a posturas teóricas cercanas a las de Carrero Blanco y, aun cuando también se reconozca haber mantenido cierto continuismo respecto a la política cultural de Fraga (Rojas Claros, 2013: 229-230, 234), algunos historiadores juzgan que la prensa se sintió incluso más presionada que anteriormente (Tusell, 1990: 764). Lo cierto es que, entre otras sanciones, se cerraron temporalmente medios como La Codorniz, Cuadernos para el Diálogo, Sábado Gráfico o Triunfo; definitivamente, editoriales como Ciencia Nueva, Ricardo Aguilera y Halcón, y así mismo se dificultó la pervivencia de ZYX y Edicusa. Algunos colaboradores de la editorial Ariel pasaron a la clandestinidad y uno de ellos, Ángel Abad, fue detenido en la editorial por policías de la brigada social.

En cuanto a $L E L$, Fernando Aragonés, hijo del subdirector de la revista y también colaborador de ella en este tiempo, recuerda aún hoy la preocupación vivida familiarmente con cada cambio de Ministerio, aunque sobre todo a partir del nombramiento de León Herrera Esteban, en octubre de 1974, y no particularmente al ser destituido Fraga (conversación personal, 4 de enero, 2018). Sin embargo, Juan Emilio Aragonés formaba parte del círculo de confianza de Manuel Fraga cuando Gabriel 
Elorriaga dirigía el gabinete técnico del ministro: Elorriaga había creado un equipo con Juan Van-Halen, Luis Borreguero, Carlos Fernández Liébana, Octavio Cabezas y Juan José Bellod (Elorriaga, 2008: 104), antiguo director este de la revista falangista La Hora, donde Juan Emilio Aragonés había publicado crítica teatral en sus inicios literarios (Aragonés, 2002: 22).

A priori, no resulta extraño pensar que, al llegar cada nuevo ministro, se informara a este de la marcha de la prensa subvencionada por el Régimen, incluso desde el punto de vista ideológico, partiendo del planteamiento por el que se había establecido, a saber, la difusión de una forma de pensar y de unas formas de cultura. En este sentido, debía estudiarse si la inversión económica quedaba compensada por esa difusión, como se ha especulado en otras investigaciones respecto a otras cabeceras de la prensa franquista (Bustamante, 1982).

Con Sánchez Bella, se convierte en más lógico aún el que se examinaran los casos particulares de aquellas, como $L E L$, que contaban con antiguos falangistas en su redacción, simpatizantes del aperturismo de Fraga e incluso relacionados con el equipo del ex ministro. Sin embargo, no han quedado rastros de ese tipo de examen por lo que respecta a $L E L$, sino del de su interés público y su viabilidad desde el punto de vista económico. Una vez realizado, la revista se vio obsequiada con un patrocinio que doblaba con mucho el anterior, a la vista de los datos ya publicados (Ballesteros, 2018: 367-368).

Cabe pensar que la estrategia seguida con esta revista se correspondiera con una de las fórmulas de "propaganda positiva" o "acción positiva" respecto a la prensa, como otras promovidas por Sánchez Bella (Muñoz Soro, 2006: 256-257; Rojas Claros, 2013: 237): consistía en contrarrestar con tácticas de propaganda las informaciones y publicaciones "inconvenientes", y para eso atraer a intelectuales y responsables de los medios hacia posiciones cercanas a las del Gobierno. Fernando Aragonés, sin embargo, no recuerda indicaciones en ningún sentido en esta época, ni tampoco recuerda haber percibido en su padre inquietud alguna al respecto (comunicación personal, 4 de enero, 2018).

Esta aportación de persona tan cercana a LEL como Fernando Aragonés resulta relevante, y también coherente con lo que se desprende de los informes de mayo de 1970 y de diciembre de 1971 publicados (Ballesteros, 2018), sin que por eso deje de resultar llamativa la falta de interés por revisar los contenidos de la revista desde el punto de vista ideológico: parece manifestar una confianza absoluta en los responsables y colaboradores de esta publicación o también, sencillamente, haberse desentendido de la cuestión ideológica en este caso. No obstante, muchos de los colaboradores más o menos habituales de LEL ocupaban ya entonces posiciones contrarias a las del régimen franquista y basta leer como pruebas los listados de nombres en los índices de Garbisu e Iglesias (2004) o las conclusiones de las investigaciones realizadas hasta el momento en torno a distintos aspectos de $L E L$. Unos y otros datos demuestran que, si por algo 
resalta $L E L$ en el conjunto de revistas del franquismo, es por su independencia y la de sus colaboradores respecto a la ideología oficialista (Ballesteros 2002, 2004, 2017a, 2017b, 2018; Garbisu 2004, 2006, 2008, 2010, 2014; Garbisu e Iglesias 2004) y por publicar lo que otros medios no se atrevían, como escribió Ponce de León al concluir su etapa de director de $L E L$ para el número del 24 de febrero de ese año:

Encima de la mesa hemos mostrado cosas que habría tachado un censor temeroso (...). Cuando nos han desafiado a publicar esto o aquello "si es posible en España", lo hemos publicado con toda naturalidad (...) Ha sido una política -amigos míos-, no de apertura, sino de admisión (...) la admisión de veras en la España profunda que nos es común; en la España viviente donde ningún español puede ser un turista, un visitante ocasional, un extranjero en su patria (1968: 3).

Otra hipótesis que permitiría entender la libertad de que gozaba LEL se resume en considerar que pudiera seguir rigiendo, al menos para ella, el criterio adoptado en época de Arias Salgado, cuando se distinguía entre publicaciones de elite y populares. En las primeras se admitían muchos juicios, opiniones y asuntos vetados en las publicaciones de grandes tiradas o en las ediciones populares y de bolsillo. De acuerdo con este criterio, se estimaría LEL como revista de minorías, para personas cultas y "bien formadas" intelectualmente. Lo contradictorio o al menos paradójico reside en que la política adoptada con la revista tras el informe de mayo de 1970, como queda claro en un artículo anterior (Ballesteros, 2018), consistió en procurar popularizarla y convertirla en plataforma de divulgación, fundamentalmente dentro de España, tanto por el aumento de la tirada como por los mecanismos de publicidad y distribución elegidos y, por tanto, tal hipótesis debe desecharse.

También podría pensarse que se trataba a $L E L$ como a publicación encaminada a ofrecer en el exterior una imagen positiva de la cultura española, dado que se distribuía en los consulados y embajadas de todo el mundo, y eso significaba también mayor independencia. La nueva paradoja es que ni en los informes, ni en las propuestas de mejora han quedado restos de interés alguno por promocionar la revista fuera de España (AGA 54, 73/482), de manera que tampoco puede sostenerse esta hipótesis.

En cualquier caso, lo que se desprende de los informes de 1970 y 1971 descritos anteriormente (Ballesteros, 2018) es el cuestionamiento de la publicación dado su carácter deficitario, tanto al solicitar el informe por parte del Ministerio como a la hora de decidir sobre su futuro. Esto se corresponde exactamente con las afirmaciones vertidas por las investigaciones realizadas hasta el momento respecto a la orientación y el tipo de gestión de la prensa oficialista y del Movimiento desde 1957, con la llegada de los "tecnócratas", y su atención dirigida a que las publicaciones resultaran rentables, cosa que pareció lograrse a lo largo de los años sesenta (Heras, 2000; Heras y Jambrino, 2014: 851-855). No se consiguió, en cambio, con $L E L$, que requería cada año mayores aportaciones económicas (AGA 54, 73/480, 73/481, 73/482). 
En otro orden de cosas, en los responsables de la revista, a través de su participación indudable tanto en la redacción del informe de mayo de 1970, como en el elevado en diciembre de 1971, se desprende un evidente esfuerzo por evitar el cierre de la publicación y cargar la responsabilidad de los déficits económicos de años anteriores en lo obsoleto de aspectos puramente técnicos y publicitarios. Seguramente pesaba en ellos y les hacía temer lo ocurrido con otras publicaciones financiadas por el Estado. No podían desconocer el hecho de que en 1968 había dejado de funcionar el semanario EI Español, fundado por el mismo Juan Aparicio iniciador La Estafeta Literaria, o que 1970 había sido el último año de publicación de la revista mensual Poesía Española, donde se repetían algunas firmas de $L E L$. De hecho, el director de Poesía Española, José García Nieto, que percibía cuatro mil quinientas pesetas mensuales por su labor en ella, disponía al mismo tiempo de una sección fija, "El cuaderno roto" en $L E L$, por la que se le pagaban mil seiscientas cincuenta pesetas. Los demás habituales de LEL percibían cantidades variables según su participación: Francisco Umbral, uno de los mejor pagados, obtenía entre trescientas y mil pesetas; Antonio Iglesias Laguna, Jiménez Martos, Carlos Murciano, entre cien y setecientas según los números (AGA 54, 73/482).

Puede entenderse también, en algunas de las propuestas y secciones añadidas en los años siguientes en $L E L$, como "Pliegos sueltos", la pretensión de rellenar el hueco dejado por Poesía Española, donde se publicaba creación, o bien de recuperar esa faceta de la perdida revista Fantasía, fundada por Aparicio poco después que $L E L$, y que solo vivió hasta 1946.

\subsection{Modificaciones adoptadas en 1971 y evolución económica}

Con la nueva oportunidad dada a $L E L$, Carranza -director general de Cultura Popular y Espectáculos- aprobó un presupuesto de gastos para el año 1971 de nueve millones de pesetas (9.015.320 pesetas) y así se lo notificó a Jesús Unciti, director de Editora Nacional, que era la encargada administrativamente de la revista, esto es, de gestionar las partidas que figuraban en los presupuestos oficiales, aunque sin disponer de la asignación de los fondos ni de otras posibles cantidades, como informó el mismo Jesús Unciti en una carta fechada en 16 de abril de 1971 (AGA 54, 73/482).

Curiosamente, si $L E L$ no solo había recibido mayor estímulo con el cambio ministerial, sino que ningún miembro de la plantilla se había visto perjudicado o expulsado y además las nuevas remesas de dinero habían permitido también mayor número de colaboradores, por su parte Editora Nacional sí modificó su equipo directivo y, en consecuencia, LEL cambió de administradores: Ricardo de la Cierva sustituyó a Jesús Unciti en julio de 1971 y trajo consigo nuevos empeños, aunque no parece que transformara la orientación que venía dándose a esta revista. 
$L E L$, a lo largo de ese año de 1971, experimentó varias modificaciones encaminadas a embellecer, modernizar y adaptar a los gustos del momento ciertos elementos de su formato y, así mismo, se aumentó su tirada y se modernizaron sus cauces de distribución, aparte de incrementarse el número de colaboraciones: si en los años sesenta se contaba para cada número con veinte colaboradores aproximadamente (veintiocho como máximo y treinta y seis en los números extraordinarios), en 1971 empezó a contarse con más de cuarenta, sobre todo debido a la sección de reseñas bibliográficas. Frente a los artículos, por los que los colaboradores cobraban cantidades muy variadas, las reseñas se pagaban de modo más igualitario, a razón de cuatrocientas pesetas cada una (AGA 54, 73/480, 73/481).

LEL se benefició, además, de otras formas de ayudas estatales, como las cuñas publicitarias gratuitas en televisión y radio. También animaba a los lectores la ventaja de un descuento del cincuenta por ciento en los teatros nacionales de Madrid y Barcelona, tal y como se anunciaba en sus páginas.

\subsubsection{Variaciones en el formato}

Por lo que respecta al formato, se han conservado distintos presupuestos (AGA 54, 73/482) en los que se especifican las condiciones con las que se publicaba la revista hasta 1971 y las propuestas para distintos arreglos, muchas de las cuales llevan las marcas o indicaciones de haberse desechado. Esto quiere decir que, antes de elaborarse el informe de 1970 a partir del cual se resolvería el futuro de $L E L$, ya hubo por parte de los responsables la previsión de ampliar la revista en diferentes sentidos, a saber, la tirada, el número de páginas y el color, y de reducirla por lo que respectaba al formato, para facilitar el manejo, lectura, exposición en quioscos y también el coleccionar y encuadernar los números. La idea consistía en incluir la misma cantidad de texto en cada página que en el formato anterior y evitar los espacios en blanco, criticados en el informe de mayo de 1970.

También se partía de la base de que, a mayor tirada, más barato proporcionalmente salía cada ejemplar y más se obtendría de las ventas, aunque aumentara el coste bruto del número. Pero había que calibrar y equilibrar bien los aumentos en las mejoras que se introdujeran.

Por ejemplo, según un presupuesto fechado el 20 de diciembre de 1969, cuando cada número constaba de cuarenta páginas, más las ocho encartadas de "Estafeta Libros", con formato de $27 \times 29$ cms y caja de $51 \times 76$ cíceros, se probó a añadir cuatro en cartulina satinada. En ese caso, la confección e impresión de cada número de cincuenta y dos páginas y cinco mil de tirada, ascendería a cien mil pesetas, y debió de parecer mucho. A mediados de 1970 se probaron otros cambios, y el 11 de mayo de ese año se presupuestó una tirada añadida de quinientos ejemplares con el mismo formato 
existente hasta la fecha, que saldría por más de nueve mil pesetas. Tampoco se adoptó, pero quizás se tuvo en cuenta en los informes del año siguiente.

El 24 de junio de 1970, ya elaborado un informe y elevado al Ministerio, se calcularon los costes de cinco mil ejemplares con un formato diferente que tampoco contó con el beneplácito de la superioridad, pero al fin se aprobaría otro de 12 de diciembre de 1970, que se corresponde con las características que pueden observarse en los ejemplares de 1971: el formato se ajustaría a 23,5×33,5 centímetros con una caja de $45 \times 64$ cíceros; se haría una impresión bicolor, y se encuadernaría por el sistema de embuchado y cosido con alambre. Se decidió tirar siete mil ejemplares por número, de cuarenta páginas, a las que se añadirían dieciséis de encarte (correspondiente a la sección "Estafeta libros").

Una forma de que no se disparase el coste consistió en no imprimir todos los ejemplares en el mismo tipo de papel: se pagaría algo más de noventa y cinco mil pesetas $(95.380$ ptas.) por cuatro mil setecientos ejemplares en papel printing de 98 gramos, y poco más de veintiuna mil por dos mil trescientos impresos en papel semibiblia de cincuenta gramos (21.625 ptas.).

Por cada mil ejemplares que se añadieran en printing habría que abonar once mil doscientas pesetas más, y por cada mil en papel semibiblia, nueve mil trescientas diez. A esto habría que añadir el pago de las dieciséis páginas de la sección "Estafeta Libros", a razón de treinta y una mil seiscientas veinte pesetas por los siete mil ejemplares, y casi tres mil pesetas por cada mil ejemplares que se añadieran (2.994 ptas.).

Pero parte fundamental de la renovación de la revista estaba en cuidar más las cubiertas, y en introducir alguna página en color. Así puede entenderse un anexo al presupuesto, fechado el 30 de marzo de 1971 y firmado por el Boletín Oficial del Estado (encargado de la impresión de $L E L$ ) en el que se especifica el valor monetario (53.680 pesetas) y las características de la impresión de siete mil ejemplares con cubierta y encarte de cuatro páginas en offset a cuatro colores, en pase de máquina simultáneo y en papel Limoges de cien gramos, incluida la fotomecánica.

Por la impresión y tipografía de las páginas de la cubierta y encarte a dos colores, división de papeles y manifiesto posterior para la incorporación, se cobrarían dieciséis mil sesenta pesetas, y por cada mil ejemplares más, cuatro mil cuatrocientas treinta pesetas, aparte de la impresión, tipografía y manipulado para la incorporación, que saldría por mil cuatrocientas noventa pesetas.

Todo esto constituía un auténtico logro para la redacción de LEL: el color le confería mayor atractivo y la estética general la modernizaba.

En mayo de 1971, aceptada la ampliación de ocho mil ejemplares, se propuso una nueva ficha técnica para ampliar las páginas de cada número, cosa que no se admitió por el momento, pero sí en otoño de aquel año (AGA 54, 73/482). 
El formato que realmente se realizó se distanciaba en diversos aspectos de los que habían ido proponiéndose, y son apreciables ya en el número 469, del 1 de junio de 1971. Constaba de cuarenta y cuatro páginas a las que se añadían dieciséis de la sección "Estafeta libros". Para las portadas se optó por una cuatricromía que podía llegar a confundirse con el todo color, en un papel cuché con brillo. Las páginas serían impresas en bicolor. El color añadido a la impresión de las páginas interiores variaba de un número a otro: naranja, azul cielo, rojo magenta, verde amarronado, marrón claro, y se presentaba en los titulares, los recuadros y filetes; era el color de fondo de algunas secciones y también de algunas ilustraciones.

Para las dieciséis páginas de la sección "La Estafeta-libros", que llevaban numeración propia y que estaban dedicadas a reseñar las novedades bibliográficas de distintas disciplinas del ámbito humanístico, se cambió el color verde de años anteriores por otro anaranjado. No se dispone de datos relativos a la elección de tal cambio, pero lo cierto es que este color, más suave, resulta más cómodo para la lectura si se compara con el verde intenso y algo oscuro utilizado con anterioridad, a tono con los uniformes de la guardia civil y la pintura de sus edificios en la época.

Los responsables miraban siempre más allá, y puede que el cierre en 1970 de Poesía Española les animara a procurar subsumir en cierto modo sus contenidos en la medida de lo posible. No en vano el director de aquella revista, José García Nieto, disponía de una sección en $L E L$ y compartían algunos colaboradores.

Así, desde el número 479, correspondiente al 1 de noviembre de 1971, apareció la sección "Pliegos sueltos", en que se ofrecían relatos, poemas e incluso breves obras teatrales. Para entonces, la revista había aumentado su número de páginas hasta cuarenta y ocho, y a partir del 15 de noviembre tendría cincuenta y seis.

Además, desde octubre, se habían introducido cuatro páginas interiores en papel cuché, dos de ellas a todo color. Esta introducción no parece del todo caprichosa, pues parece producir en el lector la impresión de enfatizar o subrayar del contenido seleccionado para ellas. Una de estas páginas se destinaba a la sección de artes plásticas, como se dijo antes, y la exhibición de fotografías de obras de escultores y pintores justificaba y hasta exigía su empleo. La otra página en color no tenía destino fijo: parte de un artículo sobre el camino de Santiago, parte de otro sobre la feria del libro de Frankfurt, el anuncio de una edición de la Biblia con la traducción de Nácar-Colunga, un artículo sobre cartografía, por poner algunos ejemplos de distintos números.

En estos momentos, el color en papel cuché de las portadas, a las que se habían sumado cuatro extra -con un coste aproximado de setenta y seis mil pesetas (76.175 ptas.)-, se acercaba más al de otras revistas, y resultaría más atractiva que cuando en los años sesenta se publicaba en blanco y negro, venía doblada por la mitad y el papel de las portadas era el mismo que el del interior, de tipo semibiblia de noventa y ocho gramos 
por metro cuadrado en dos mil trescientos ejemplares, y del doble la resma en dos mil setecientos ejemplares.

\subsubsection{Variaciones en la tirada}

Por lo que respecta a la tirada, como se ha adelantado ya, después de varios intentos fallidos por aumentar la de cinco mil ejemplares en los últimos meses de 1970 sin obtener los permisos necesarios, por fin de cada número empezaron a tirarse siete mil a partir de enero de 1971; pero desde abril del mismo año, la tirada ascendió a once mil, según notificación de Carranza a Unciti (3 de abril de 1971) y desde junio empezaron a imprimirse quince mil (carta de 5 de junio de 1971), tras firmarse un convenio definitivo con Marco Ibérica, Distribución de Ediciones S.A. (MIDESA) (AGA 54, 73/482).

Debe tenerse en cuenta que MIDESA no era una empresa pública, sino una distribuidora creada por Salvat en 1964 y principal distribuidora de publicaciones en la España de 1970, junto con la Sociedad General Española de Librería. Con veinte mil puntos de venta, disponía de reparto diario y admitía la devolución de ejemplares. Por otra parte, siempre había mantenido buenas relaciones con el régimen franquista (Rojas Claros, 2013: 157-159). Es muy probable que en la elección de la distribuidora estuviera presente el éxito obtenido por la colección RTV de Salvat y Alianza en 1969, después de ser las adjudicatarias de un concurso para la edición de cien obras dentro del plan estatal de promover la cultura en España.

Pero esa tirada de quince mil ejemplares no se veía como algo permanente desde las instancias superiores: Carranza, en su calidad de director general de Cultura Popular y Espectáculos, en la notificación favorable para su ejecución, fechada el 5 de junio y dirigida a Fulgencio Luengo como gerente comercial de $L E L$, le advertía de que podía también reducirse en los meses de verano en previsión de una menor demanda. El propósito de la Dirección General era la de ajustar las tiradas “en el mayor grado posible a las capacidades reales de este mercado específico, aunque siempre puesta la mirada en una cada vez mayor difusión de la revista" (AGA 54, 73/482). De todos modos, imponía al gerente la necesidad de mantener informado debidamente al director y de sugerirle las tiradas más convenientes en cada época.

\subsubsection{Distribución y ventas}

A finales de 1971, se elaboró otro informe no explicado en el artículo en que se describe (Ballesteros, 2018: 368) por lo que respecta a la siguiente cuestión: en tal informe, se decía que, sin ser el momento para presentar los datos relativos a ingresos, se preveía un aumento en las ventas que permitiera llegar al objetivo de tirar veinte mil y veinticinco mil ejemplares de cada número, con lo que $L E L$ se situaría en el nivel de las revistas culturales más demandadas sin que subieran significativamente los gastos, pues se compensarían con los ingresos y con una bajada en los costes de impresión. Esta previsión de mayores ingresos se cifraba en que, desde abril de 1971, el precio del 
ejemplar había ascendido a veinte pesetas, frente a las quince que se pagaba durante los años sesenta. Igualmente, se pensaba en mayores acopios de capital a partir de nuevas contrataciones publicitarias.

Pero tras ese "este no es lugar" que se tecleó en el documento cabe especular que había la intención de no proporcionar los datos existentes por no convenirles a quienes redactaron tal informe, a todas luces personas implicadas personalmente en el mantenimiento de la revista. Desgraciadamente, no parecen haberse conservado los datos concretos sobre las ventas de 1971. No obstante, resulta bastante evidente que los primeros meses sí debieron de responder a las expectativas, pues de otro modo no se hubiera resuelto aumentar las tiradas a mitad de año a once mil y luego a quince mil ejemplares, pero la trayectoria posterior arroja indicadores muy distintos: los datos referentes a 1972 conservados sirven para estimar una evolución de gastos y ventas muy distante de lo previsto y así se comprenden las medidas adoptadas en los años siguientes.

Por una parte, no se han conservado documentos que acrediten el que Luengo, como gerente, fuera proponiendo una modificación de las tiradas conforme a la demanda prevista, según se le había pedido, sino que se mantuvieron los quince mil ejemplares también en 1972.

Por otro lado, Midesa distribuyó en torno a once mil trescientos los dos primeros meses de este año, y bajó luego a diez mil los meses de marzo y abril. A partir de mayo y hasta julio, distribuyó poco más de ocho mil.

Por su parte, la Redacción distribuyó doscientos los dos primeros meses, luego aumentó a quinientos y desde abril pasó a distribuir trescientos.

La Dirección General de Cultura se mantuvo en los ochocientos, mientras que la Delegación del Ministerio de Información y Turismo contó con seiscientos diez los seis primeros meses del año y Editora Nacional con cincuenta.

Los suscriptores gratuitos fueron aumentando progresivamente desde seiscientos diecisiete en enero hasta seiscientos noventa y ocho en julio.

Más interesante es comprobar que aumentaron en cincuenta los suscriptores que pagaban, de setecientos cincuenta a ochocientos.

Por su parte, los jefes de edición y el gerente, Luengo, disponían de veinticinco ejemplares. Además, en los dos últimos meses se encargaron de distribuir cuatrocientos (AGA 54, 73/482).

Para entender estas cifras, debe considerarse que, aparte de la distribuidora MIDESA, no se prescindió del todo de los mecanismos tradicionales de LEL: el Ateneo de Madrid, del que LEL había dependido administrativamente hasta marzo de 1964, mantenía la 
distribución del mismo número de ejemplares que anteriormente, y así mismo llegaba a los delegados de Información y Turismo en sus respectivas sedes.

\section{Fracaso de la promoción}

\subsection{Las cifras del fiasco}

Los gastos reales de 1972 sobrepasaron los diez millones de pesetas (10.135.211 ptas.) cuando el presupuesto era de $9.584,784$. Eso significa que se mantuvo un año más la tendencia de aumentar el gasto en medio millón de pesetas aproximado respecto al presupuesto (AGA 54, 73/482).

Se dispone de los datos exactos de las ventas entre enero y julio de 1972: las de los suscriptores oscilaron entre los mil setecientos y los mil ochocientos ejemplares, y las de los no suscriptores entre los tres mil y los cuatro mil, de modo que las ventas totales se encontraron entre los cuatro mil setecientos veintisiete y nunca sobrepasaron los cinco mil setecientos ejemplares, lo que significaba un porcentaje de en torno al treinta y uno y treinta y siete por ciento de la tirada (AGA 54, 73/482).

Estas cifras permiten sospechar la veracidad de lo expuesto anteriormente respecto a las ventas de 1971: resulta extraño que, tras acabar ese año con tan buenos auspicios, se produjera una drástica reducción de las ventas, hasta niveles cercanos a los de los años previos a los cambios, como no fuera que la curiosidad llevara al público potencial a adquirir algunos números, pero luego muchos lectores quedaran decepcionados por su contenido.

También se había contado con unos ingresos crecientes provenientes de la publicidad. Los correspondientes por este concepto a los cuatro primeros números de ese año de 1972 fueron los siguientes:

\begin{tabular}{llll} 
Número & $\begin{array}{l}\text { Facturado en } \\
\text { pesetas }\end{array}$ & $\begin{array}{l}\text { Comisiones en } \\
\text { pesetas }\end{array}$ & $\begin{array}{l}\text { Cobrado líquido en } \\
\text { pesetas }\end{array}$ \\
\hline 483 & 24.250 & $8.487,50$ & $14.762,50$ \\
484 & 8.750 & $3.062,50$ & $5.187,50$ \\
485 & 18.000 & 5.400 & 12.100 \\
486 & 8.500 & 2.975 & 4.775 \\
\hline
\end{tabular}


Teniendo en cuenta que la inversión aproximada por cada cuatro números ascendía a más de ochocientas mil pesetas, las cerca de treinta y siete mil procedentes de los anuncios cubrían una parte muy exigua de los gastos.

Por lo que respecta a la distribución, en los últimos meses de 1972, se habían modificado ligeramente las cifras mencionadas al final del apartado anterior, a la vista de los ejemplares sobrantes del mes de julio, lo cual quiere decir que la reducción de ventas no se estimó pasajera: MIDESA procuró distribuir diez mil ejemplares pero, pese a aumentar en más de doscientos los suscriptores de pago (1995 para el número 506, 1969 para el número 507, 2025 para el 508) y en más de cien los gratuitos (737 en los números 506, 507, o 746 en el 508), no por eso disminuyó el número de ejemplares sobrantes respecto a lo visto en el mes de julio: entre quinientos ochenta y tres del número 506 y seiscientos ochenta y cuatro del número 508.

Por otra parte, los jefes de la revista eran también agentes gestores de publicidad, y mientras que Fulgencio Luengo Hernández se llevaba de comisión el diez por ciento sobre las facturas, Eladio Cabañero, Ramón Solís y Juan Emilio Aragonés se llevaban el veinticinco por ciento. La comisión de Publicitaria Catalana y Publidis ascendía al cuarenta por ciento, y la de Publicidad Cid al treinta por ciento.

Estos datos, enfrentados a los gastos efectuados y cotejados con los de los años previos a los cambios, parecen evidenciar un rotundo fracaso en las aspiraciones de la revista de convertirse en una publicación con un alcance similar a otras de condición en algún aspecto semejante, pero independientes del Estado.

\subsection{Evolución desde las últimas disposiciones durante el Ministerio de Sánchez Bella hasta el fin del franquismo}

Como es lógico, se decidió reducir la tirada, de modo que en 1973 empezaron a salir de la imprenta del Boletín Oficial del Estado siete mil ejemplares por número, como a principios de 1971 (AGA 54, 73/482).

En cualquier caso, la situación de $L E L$, pese a las peculiaridades de su contenido, no resultaba anómala en el conjunto de las publicaciones periódicas financiadas por el régimen franquista: diversos estudios han demostrado que, pese a los intentos reformadores de los años setenta, esta no solo resultaba deficitaria, porque deficitaria y necesitada de subvención había sido siempre, sino que cada vez se vendía peor, quedaba malparada al compararse con la prensa de las empresas privadas (Alférez, 
1986; Martín de la Guardia, 1994; Martín de la Guardia, 2000), y se resentía de los principios por los que se había fundado, a saber, la difusión de la ideología del régimen franquista y del tipo de cultura que pretendía promover (Iglesias, 1975). Solo que todos sabían el peligro de cierre que se cernía sobre estas publicaciones cuando los años setenta traían consigo otras expectativas sociales y políticas, y los responsables de $L E L$ parecían decididos a luchar por su supervivencia a todo trance.

Por eso, seguramente en la redacción se vio con cierto alivio el que se mantuvieran los siete mil ejemplares de tirada en los últimos meses de 1973: A Fernando de Liñán y Zofio se le confió el Ministerio desde la salida de Sánchez Bella en junio de ese año hasta que el asesinato de Carrero Blanco, en diciembre de ese año, exigió un cambio de gobierno. En esos escasos meses se dieron las instrucciones al respecto por parte de la Dirección General de Cultura Popular, y fueron notificadas por Luengo al jefe de la sección comercial el 14 de noviembre de aquel año (AGA 54, 73/482).

MIDESA, pese a sus exigencias iniciales, siguió aceptando distribuir la revista, incluso con una cantidad de ejemplares cuatro veces inferior. Por lo demás, se observa que se mantenía el número de suscriptores, aunque también se había incrementado el de quienes recibían gratis $L E L$. Véanse las cifras del plan de distribución:

$\begin{array}{ll}\text { DISTRIBUCIÓN } & \text { NÚMERO DE EJEMPLARES } \\ \text { Suscriptores de pago } & 2.073 \\ \text { Suscriptores gratuitos } & 900 \\ \text { Dirección General de Cultura Popular } & 700 \\ \text { Jefes de Editora Nacional } & 15 \\ \text { Librerías de Editora Nacional } & 50 \\ \text { La Estafeta Literaria } & 75 \\ \text { MIDESA } & 3.200\end{array}$

Según esto, no puede atribuirse a la "crisis del petróleo", iniciada en ese mes de octubre de 1973, ni a la subida de precios, como suponen Iglesias y Garbisu (2004: 17) la restricción económica de la revista, dado que en España las consecuencias de tal crisis no se percibirían sino después. Más bien suponía atenerse a la realidad de que la revista no alcanzó sus objetivos respecto a los lectores potenciales, ni logró vencer en su competición con otros medios, y se devolvían gran parte de los ejemplares distribuidos a los puntos de venta de las distintas provincias.

Por lo demás, el tipo de contenido se mantuvo aproximadamente igual: en torno a las cuarenta páginas de artículos, reportajes, entrevistas, críticas y noticias sobre arte, literatura, cinematografía, las cuatro páginas de los pliegos de ficción... pero ya no 
dieciséis, sino doce, aunque muy bien nutridas, eran las asignadas a reseñas bibliográficas sobre las publicaciones recientes en distintas disciplinas. Tampoco cambiaron los responsables de las distintas secciones, aunque el número de colaboradores quedaba siempre abierto.

Con Pío Cabanillas al frente del Ministerio, después del asesinato de Carrero Blanco y del ascenso de Arias Navarro, las posturas más intransigentes del Régimen advirtieron una excesiva tolerancia hacia la prensa y forzaron la destitución de este ministro, que se hizo efectiva el 28 de octubre de 1974. Pero en $L E L$ no se perciben cambios significativos por lo que a las cuestiones aquí tratadas concierne. Incluso se mantuvieron los sueldos fijos de la Redacción y de los colaboradores habituales.

La revista tampoco pareció sufrir ningún revés en la época del ministro Herrera Esteban, tan temido en la Redacción (Aragonés, comunicación personal, 4 de enero, 2018). Porque había razones para temer: en primer lugar, por los motivos de la destitución de Pío Cabanillas, suficientes para entender que no iban a permitirse niveles de tolerancia como aquellos que habían sacado del Gobierno a este ministro; después, comprobar cómo se sucedían un día detrás de otro las multas, los secuestros de ediciones, la suspensión de publicaciones... y aunque casi todas las cabeceras habían presentado conflictos en periodos anteriores, entre ellas Cambio 16 (García Martín, 2013: 307-324), Triunfo (García Galindo, 2012: 42) o las humorísticas que se propasaban en sus licencias como Por Favor, La Codorniz, Hermano Lobo o Sábado Gráfico, también sufrían multas otras menos problemáticas. Vista la actitud de libertad sostenida por $L E L$, cabía esperar en cualquier momento algún tipo de sanción.

Por lo demás, MIDESA, durante estos meses, siguió ajustándose a las necesidades de la revista, y ya solo recibía para su distribución dos mil setecientos ejemplares de cada número. Aún así, según los documentos conservados, de los números 553 y 554, correspondientes al mes de diciembre de 1974, se le devolvieron seiscientos veinticinco y seiscientos dieciséis ejemplares, respectivamente (AGA 54, 73/482).

Por entonces se ordenó a través de la dirección de Cultura Popular que Editora Nacional sustituyera a MIDESA y, curiosamente, se ordenó que por cada número se tiraran ocho mil ejemplares. El departamento de distribución de Editora Nacional acometió una prospección de mercado en cincuenta provincias, en cada una de las cuales procuraría contar con el distribuidor regional más idóneo. De modo similar a lo ocurrido con MIDESA, los distribuidores solicitaban mayor número de ejemplares para poder cubrir los puntos de venta disponibles, y cifraban la necesidad de contar al menos con diez mil, lo que suponía un auténtico desfase respecto a lo realmente vendido posteriormente.

Se preveía, en cualquier caso, rotar los números devueltos por los centros nacionales y extranjeros de enseñanza, universidades, colegios mayores o agregados culturales, sin 
descuidar contar con algunos para posibles solicitudes de números atrasados (AGA 54, 73/482).

Se cuenta con los números previstos para la comercialización desde el primero mayo de ese año.

\begin{tabular}{ll} 
DISTRIBUCIÓN & NÚMERO DE EJEMPLARES \\
\hline Suscriptores de pago & 2.529 \\
Suscriptores gratuitos & 473 \\
Dirección General de Cultura Popular & 800 \\
Distribución en cincuenta provincias & 3.998 \\
Dirección de La Estafeta Literaria & 200 \\
Totales & 8.000
\end{tabular}

(AGA 54, 73/482).

Es de notar que había crecido el número de suscriptores en este tiempo en casi quinientos, y en cambio se había reducido a la mitad el número de envíos gratuitos. La muerte de Franco no significó un declive total para LEL: había logrado sobreponerse a las dificultades de los cambios políticos y a la enorme competencia de otras publicaciones, y aún lograría mantenerse con los mismos responsables al frente durante la Transición Democrática, incluso hasta 1979, y luego con grandes cambios de formato, responsables y contenidos bajo la denominación Nueva Estafeta.

\section{Conclusiones}

El estudio de los documentos relativos a esta publicación en los años cruciales del tardofranquismo indica que siguió una trayectoria en parte paralela a la de otras publicaciones financiadas por el Estado, en cuanto a que mantuvo su carácter deficitario y requirió mayores aportaciones estatales conforme pasaron los años. Sin embargo, su trayectoria presenta divergencias esenciales: frente al cierre que sufrieron El Español o Poesía Española, LEL consiguió mayores subvenciones para adaptarla a las exigencias del mercado.

No obstante, se verían frustradas las expectativas creadas respecto a que los esfuerzos traerían aparejadas ventas proporcionales a las de las revistas privadas con algún contenido similar, pues los datos conservados y presentados en este artículo 
demuestran que ni la modernización en las condiciones de publicidad y distribución, ni en las del formato, ni el aumento de las tiradas y los contenidos repercutieron a medio plazo conforme a lo esperado.

Por otra parte, en este artículo se demuestra que pese a los vínculos y relaciones personales habidas entre los miembros de la Redacción de $L E L$ y el gabinete ministerial anterior al de Sánchez Bella, la revista recibió un decidido apoyo durante el Ministerio de este, en términos de que los colaboradores pudieron mantener una independencia y libertad de expresión que venía siendo un rasgo de identidad de la revista.

Los documentos prueban también que los continuos cambios de ministros en los años setenta y su diversidad de criterios en ningún caso parecieron perjudicar a $L E L$ y que frente a las posiciones respecto a la prensa que los historiadores atribuyen a tales ministros, y los propios temores habidos en el cuerpo de la redacción de la revista, nunca parecieron revisarse ni cuestionarse ideológicamente sus contenidos, ni tampoco a sus colaboradores.

La única limitación que acusó la publicación por parte del Estado después del intento fallido fue el reajuste de la tirada a las ventas reales, de modo que el incremento respecto a los años sesenta fue de dos mil ejemplares: si hasta 1970 se tiraban cinco mil ejemplares por número (diez mil por dos números extraordinarios anuales), a partir de la segunda mitad de 1972 hasta la muerte de Franco se tirarían siete mil, aunque llegaran a tirarse quince mil entre mayo de 1971 y mayo de 1972.

\section{Fuentes y bibliografía}

\section{Fuentes}

ARCHIVO GENERAL DE LA ADMINISTRACIÓN (ALCALÁ DE HENARES). Sección Cultura (54). cajas 73/480, 73/481, 73/482.

ARAGONÉS CARAZO, F. (2002): (2018) Comunicación personal con Ana Isabel Ballesteros Dorado. 4 de enero de 2018.

PONCE DE LEÓN, L. (1968): “Este número 390 y adiós”, en La Estafeta Literaria, no 390, 1968, pp. 2-3.

\section{Bibliografía}

ALFÉREZ, A. (1986): Cuarto poder en España. La prensa desde la Ley Fraga 1966, Barcelona, Plaza \& Janés. 
ALTARES, P. (2004): "Los semanarios españoles”, en Aracil Martí, R., Mayayo, A., Segura, A. (editores), Ensenyament, cultura, justicia, Barcelona, Universitat de Barcelona, 2004, pp. 137-147.

ÁLVAREZ PUGA, E. (1974): MATESA, más allá del escándalo, Barcelona, Dopesa.

ARAGONÉS CARAZO, F. (2002): Juan Emilio Aragonés, su vida y su obra. Un ejemplo de aragonesismo y humanidad, Huesca, Amigos de Serrablo.

BALLESTEROS DORADO, A. I. (2002): "Seis dramaturgos con título nobiliario en La Estafeta Literaria", en Aportes, no 49, 2002, pp. 4-22.

_ (2004): "La presencia de Leopoldo Alas en La Estafeta Literaria”, en Leopoldo Alas "Clarín" y su época, Madrid, Universidad CEU-San Pablo, pp. 102-115.

_ (2017a): "Juan Emilio Aragonés Daroca", en Pérez-Rasilla, E., Doménech, F. (editores), Historia y antología de la crítica teatral en España, Madrid, Ministerio de Educación, Cultura y Deporte, INAEM, Centro Dramático nacional, tomo II, pp. 367-380.

_ (2017b): “Luis Molero Manglano”, en Pérez-Rasilla, E., Doménech, F. (editores), Historia y antología de la crítica teatral en España, Madrid, Ministerio de Educación, Cultura y Deporte, INAEM, Centro Dramático nacional, tomo II, pp. 422-433.

_ (2017c) "Julio Manegat", en Pérez-Rasilla, E., Doménech, F. (editores), Historia y antología de la crítica teatral en España, Madrid, Ministerio de Educación, Cultura y Deporte, INAEM, Centro Dramático nacional, tomo II, pp. 337-342.

_ (2018): "La Estafeta Literaria. Pervivencia y nuevo impulso de una revista cultural franquista entre 1970 y 1972", en Historia y Comunicación Social, no 23 (2), 2018, pp. 355-370 http://dx.doi.org/10.5209/HICS.62262

BUSTAMANTE RAMÍREZ, E. (1982): Los amos de la información en España, Madrid, Akal.

ELORRIAGA, G. (2008): El camino de la concordia: de la cárcel al parlamento, Barcelona, Debate.

EZCURRA, J. Á. (1995): "Crónica de un empeño dificultoso", en Alted Vigil, A., Paul Aubert, P. (editores), Triunfo en su época. Jornadas organizadas por la Casa Velázquez, Madrid, Casa Velázquez, Ediciones Pléyades, pp. 365-667.

FERNÁNDEZ, L. M. (2014): Escritores y televisión durante el Franquismo (1956-1975), Salamanca, Ediciones de la Universidad de Salamanca.

FERNÁNDEZ MARTÍNEZ, P. (2010): "El idioma nuestro de cada día": análisis del lenguaje en la quinta etapa de La Estafeta Literaria", en La Estafeta Literaria y su contribución a la difusión de la cultura española del S. XX, Madrid, Sílex, pp. 11-62. 
_ (2012a): "Los análisis filológicos de Gerardo Diego en La Estafeta Literaria”, en Valdivieso, J. H, Ruiz-Fornells, E. (editores), El español, integrador de culturas, Méjico, Ensayos Orbis Press, pp. 107-117.

_ (2012b): "Papeletas para un argot de hoy: Estudios lexicográficos en la Estafeta Literaria", en Nombedeu, A. et alts. (editores), Avances de Lexicografía Hispánica (II), Tarragona, Universitat Rovira i Virgili, pp. 329-340.

GARBISU BUESA, M. (2004): “La literatura francesa en la primera Estafeta Literaria”, en Hesperia: Anuario de Filología Hispánica, no 7, pp. 89-104.

_ (2006): “La Estafeta Literaria (1944-2001), vehículo de difusión de nuevos escritores: el caso de Francisco Umbral", en Hernández Guerrero, J. A. (editor), Retórica y periodismo. Actas del V seminario Emilio Castelar, Cádiz, Universidad de Cádiz. Servicio de Publicaciones, pp. 263-276.

_ (2008): "La literatura extranjera de creación en Nueva Estafeta: un medio de entrada en la España de la nueva democracia", en Rilce. Revista de Filología Hispánica, no 24.2, pp. 285-305.

_ (2010): “La literatura extranjera en La Estafeta Literaria: 1957 y Rafael Morales como punto de inflexión", en La Estafeta Literaria y su contribución a la difusión de la cultura del siglo XX, Madrid, Sílex, pp. 63-101.

_ (2014): "Los inicios en prensa de Francisco Umbral: las colaboraciones en La Estafeta Literaria", en Dicenda, no 32, pp. 155-183.

_ e Iglesias Berzal, M. (2004): Índices de La Estafeta Literaria (1944-2001). Contenidos literarios de la revista, Madrid, Fragua.

IGLESIAS GONZÁLEZ, F. (1975): “Un imperio informativo: Prensa y Radio del Movimiento", en Nuestro Tiempo, 1 no 250, pp. 67-77.

GARCÍA GALINDO, J. A. (2012): “El contexto periodístico de Triunfo (1962-1982)”, en Romero Portillo, J. (editor), Triunfo: una revista abierta al sur, Junta de Andalucía, Fundación Pública Andaluza, Centro de Estudios Andaluces, pp. 41-46.

GARCÍA JIMÉNEZ, J. (1980): Radiotelevisión y política cultural en el franquismo, Madrid, CSIC.

GARCÍA MARTíN, J. A. (2013): La transición a través de Cambio 16, Madrid, Universidad Rey Juan Carlos. Disponible en Internet (1-2-1019) https://eciencia.urjc.es/bitstream/handle/10115/12263/Tesis\%20doctoral\%20Ju an\%20Andr\%C3\%A9s\%20Garc\%C3\%ADa\%20Mart\%C3\%ADn.pdf?sequence=1\&is Allowed $=y$ 
GONZÁLEZ ARIZA, F. (2010): "El mundo editorial en La Estafeta Literaria", en La Estafeta Literaria y su contribución a la difusión de la cultura del siglo xx, Madrid, Sílex, 139170.

HERAS PEDROSA, C. de las (2000): La prensa del movimiento y su gestión publicitaria, Málaga, Spicum.

- y JAMBRINO MALDONADO, C. (2014): "La publicidad en la prensa del Movimiento", en Historia y Comunicación Social, № 19 (febrero de 2014), pp. 847860.

MARTÍN DE LA GUARDIA, R. (1994): Información y propaganda en la prensa del Movimiento. Libertad de Valladolid, (1931-1979), Valladolid, Secretariado de Publicaciones de la Universidad de Valladolid.

_ (2000): "Los últimos intentos reformadores de la prensa del Movimiento (19751976)", en Ámbitos: Revista Internacional de Comunicación, no 3-4, 2000, pp. 169180. Disponible en Internet (11-11-2018) https://idus.us.es/xmlui/handle/11441/67187

MATEOS, A. y SOTO CARMONA, Á. (1997): El final del franquismo, 1959-1975. La transformación de la sociedad española, Madrid, Temas de Hoy.

MAURICE, J. (2005): "Franquismo y literatura: la novela en La Estafeta Literaria", en Desvois, J. M. (editor), Prensa, impresos, lectura en el mundo hispánico contemporáneo: homenaje a Jean-François Botrel, Bordeaux, Université Michel de Montaigne Bordeaux 3: PILAR. pp. 315-322.

MUÑOZ SORO, J. (2005): Cuadernos para el Diálogo, 1963-1976: una historia cultural del segundo franquismo, Marcial Pons, Ediciones de Historia S.A.

NAVARRO RUBIO, M. (1978): El caso Matesa, Madrid, Dossat.

ROJAS CLAROS, F. (2013): Dirigismo cultural y disidencia editorial en España (19621973), Alicante, Publicaciones Universidad de Alicante.

TUSELL, J. (1990): Historia de España. Siglo XX, Madrid, Historia 16.

ZALBIDEA BENGOA, B. (1996): La Prensa del Movimiento en España: 1936-1983, Bilbao, Universidad del País Vasco. 